\title{
A University-designed Middle School Remote Summer Engineering Academy
}

\section{Mrs. Zahraa Krayem Stuart, Stony Brook University}

Zahraa Krayem Stuart received Bachelor of Engineering in Electrical Engineering from Stony Brook University in 2016. In 2017, she joined the PhD program in Electrical Engineering Statistical Signal Processing. Zahraa designs, develops, and instructs engineering teaching laboratories for both high school and middle school students since 2016.

\section{Dr. Monica Bugallo, Stony Brook University}

Mónica F. Bugallo is the Vice Provost of Faculty Affairs and Diversity, Equity \& Inclusion and Professor of Electrical and Computer Engineering at Stony Brook University. She received her B.S., M.S, and $\mathrm{Ph}$. D. degrees in computer science from University of A Coruña, Spain. She joined the Department of Electrical and Computer Engineering at Stony Brook University in 2002. Her research interests are in the field of statistical signal processing, with emphasis on the theory of Monte Carlo methods and its application to different disciplines including biomedicine, ecology, sensor networks, and finance. In addition, she has focused on STEM education and has initiated several successful programs with the purpose of engaging students at all academic stages in the excitement of engineering and research, with focus on underrepresented groups. She has authored and coauthored two book chapters and more than 185 journal papers and refereed conference articles.

Bugallo is a senior member of the IEEE, serves on several of its technical committees and is the current vice chair of the IEEE Signal Processing Society Signal Processing Theory and Methods Technical Committee and the chair of the EURASIP Special Area Team on Theoretical and Methodological Trends in Signal Processing as well as an elected member of the IEEE Signal Processing Society Sensor Array and Multichannel Technical Committee. She has been part of the technical committee and has organized various professional conferences and workshops. She has received several prestigious research and education awards including the State University of New York (SUNY) Chancellor's Award for Excellence in Teaching (2017), the 2019 Ada Byron Award of the Galician Society of Computer Engineers (Spain) for a successful professional career path that inspires women to engineering study and careers, the Best Paper Award in the IEEE Signal Processing Magazine 2007 as coauthor of a paper entitled Particle Filtering, the IEEE Outstanding Young Engineer Award (2009), for development and application of computational methods for sequential signal processing, the IEEE Athanasios Papoulis Award (2011), for innovative educational outreach that has inspired high school students and college level women to study engineering, the Higher Education Resource Services (HERS) Clare Boothe Luce (CBL) Scholarship Award (2017), and the Chair of Excellence by the Universidad Carlos III de Madrid-Banco de Santander (Spain) (2012).

\section{Mrs. Kathleen Dinota, Stony Brook University}

Kathleen Dinota received her B.S. in Marine Science and M.S. in Secondary Education, retiring in 2017 after teaching in public schools on Long Island, NY for 31 years. During the course of her career, she taught earth science, biology and chemistry as well as science research. Kathleen has also worked in test development at NY State Education Department as an Education Specialist for the Regents Physical Setting Chemistry exam for the past 20 years. She is a former NYS Master Teacher. Kathleen currently serves as the Engineering Education Project Director and Outreach Coordinator at Stony Brook University. She helped to develop the Engineering Academy, ensuring alignment to state education standards and use of appropriate pedagogy and managed all logistics related to the camp. Kathleen continues to work with school districts and the University to provide high-quality experiences that expose students to various disciplines of engineering.

\section{Mr. Hechuan Wang, Stony Brook University}

Hechuan Wang received his B.S. degree in Automation from Hefei University of Technology, China, in 2014 and is currently a Ph.D. candidate at Stony Brook University. During his Ph.D. study, he actively participated in the university outreach program, where he designed two remote STEM academies that taught 


\section{ASEE ANNUAL CONFERENCE \\ Virtual Meeting | July 26-29, 2021 | Pacific Daylight Time

Electrical Engineering to 6-8th grades online. His educational interest is in exposing young students to engineering according to the Next Generation Science Standards (NGSS) and converting the traditional in-lab experiments into remote activities offered online.

Amanda Esposito, Stony Brook University 


\title{
University-designed Middle School Remote Summer Engineering Academy
}

\begin{abstract}
The K-12 education platform has drastically taken a different route since the onset of the COVID-19 global pandemic. With the classroom being transitioned to online, educators are presented with many challenges to keep their class engaged. The curriculum of Science, Technology, Engineering, and Mathematics (STEM) is possibly the toughest to adapt to remote instruction, given that participants may no longer have access to many school labs or school STEM resources. Moreover, science and engineering in-person outreach programs are no longer feasible due to the pandemic and one cannot help but question whether the adoption of the hands-on instructional strategies pioneered by the Next Generation Science Standards (NGSS) will be able to be maintained. Faculty and graduate assistants at Stony Brook University in New York developed a unique, remote, yet hands-on engineering opportunity for middle school participants over the course of five 90-minute sessions of synchronous learning. Asynchronous learning was also available through a website populated with detailed manuals and short videos demonstrating the activities and office hours helped participants to clarify questions and finish their designs and prototypes. Through this Engineering Academy experience, participants $(\mathrm{N}=90)$, from across Long Island, were exposed to real-world applications of 3D printing and electrical and materials/chemical engineering, as well as the engineering design process. Questionnaires were administered pre- and post-every session to learn about participants' engineering literacy while post Academy surveys were collected to analyze both participants' engineering self-efficacy and knowledge. Future science and engineering curricular efforts may utilize and replicate the learned best practices to ensure a sustainable implementation of the NGSS via online or hybrid (online and in-person) learning opportunities.
\end{abstract}

\section{Introduction}

Pedagogical adaptability was on full display this academic year given the outbreak and spread of COVID-19 in the United States and around the world. Doors were shut and businesses were closed, but learning did not stop. K-12 educators faced an unprecedented challenge and at the same time unique opportunity to re-think the delivery of instruction. Remote learning was fraught with challenges and difficulties and best practices had yet to be established. Most teachers lacked the training in remote instruction [1] and teachers of STEM had an added challenge to transition their labs and hands-on activity remotely [2]. Furthermore, the adoption of the NGSS [3] had propelled engineering education to the forefront of the national discussion with questions arising as to its sustainability during the pandemic and the hardship of transitioning to online learning.

Over the past years, there has been a huge effort of outreach programs and informal science training to incorporate the NGSS standards into the curriculum. Engineering outreach programs have a history of success in the US and arose out of the demand to meet societal needs and keep the US technologically competitive [4]. In order to meet the demands placed upon our nation in terms of economic development and technological enhancement, it is important to begin with fostering an appreciation and awareness for careers in engineering as early as in K-12 to get participants interested, exposed, and intrigued by engineering and its application to solving problems [4][5].

Exposure to STEM is critical in developing an interest within younger participants [6] and a concrete literature review on different STEM outreach programs and outreach optimization for participants ranging from pre-K to undergraduate students can be found in [7]. Many outreach programs have had a national success, such as Project Lead the Way [8], the Infinity Project [9], and The National Girls Collaborative Project [10]. Other efforts that followed the lead of the engineering outreach programs to create interest and increase pre-college engineering literacy among middle and high school participants are summarized in $[11][12][13][14][15][16]$. 
The latest development initiated during the months of the pandemic consisted of creating a remote engineering outreach program that aligns with the NGSS, maintains the long history of accomplishments in engineering outreach programs [7], and establishes best practices for transitioning outreach efforts and engineering labs to online learning. This was at the heart of our effort at the remote Summer Engineering Academy outreach program that was spearheaded as a template for synchronous and asynchronous remote learning for middle school participants.

\section{Program Planning}

When the university banned all in-person meetings for the summer of 2020, it was decided that a remote engineering experience for middle school participants would be offered as a pilot program to help develop future remote programs. In this paper, we will describe our pilot Engineering Academy from planning to curriculum development and delivery. The Academy was conducted for a total of five sessions over a period of two and a half weeks in July of 2020 and covered a variety of topics related to engineering. Both synchronous and asynchronous learning were utilized to give participants the leverage to optimize their design and add their individual touch to help improve their interest and self-efficacy [17].

Planning for the Summer Engineering Academy was conducted via weekly Zoom meetings with the program coordinator, all instructors, and teaching assistants. Through the course of the planning process, activities were proposed, and a sequence of instruction was determined. In addition, a Slack (an online messaging platform) workspace was created and shared with the instructional team for general communication. The planning process included activities and lesson plans that would be included each day, the roles of the instructor and teaching assistants, and the list of materials needed to complete each activity. Local school districts were informed of the Academy through an email sent to district superintendents for distribution to science directors and teachers, recruiting rising seventh and eighth graders. For registration purposes, a Google Form was created. Originally, the plan was to enroll approximately 30 participants, with a possibility of up to 40 participants, if interest warranted. Within five days of the opening of the registration window, 125 participants had completed the registration form. It was decided at that time to expand the instructional team to include an additional instructor and three more teaching assistants and to run the Academy over a total of four sections, two running concurrently in the morning and two running in the afternoon. An email to confirm interest and registration was sent to all that completed the original registration form and a total of 90 participants confirmed their participation.

The Academy sessions were scheduled to run for ninety minutes on Mondays and Thursdays over a course of two and a half weeks. This was done intentionally so as not to overwhelm participants that had spent the last semester of school in remote instruction and to retain interest and engagement. Each section of the Academy consisted of approximately 24 participants with one instructor and three teaching assistants. The participants were assigned to work with a specific teaching assistant for the duration of the Academy. One section of the Academy was composed of only females, while the remaining three sections were heterogeneously grouped by gender and grade level. The program coordinator's function during each session was to oversee logistics for all sections, including admitting participants to the meeting, launching polls and creating breakout rooms. Assistance was offered to participants in the form of an "office hour" each afternoon of the Academy. To access the Academy, the program coordinator created Zoom meetings and emailed links to all participants. For ease of access, the Zoom was created as a repeating meeting so that the same link could be used for all sessions. An email reminder was sent to all participants during the morning of each session, reminding them of 
the link. Materials were ordered and kits were assembled at the university and mailed via USPS flat rate boxes to all participants in advance of the Academy.

During each session, whole-group instruction in theory and concepts was conducted by using PowerPoint presentations and Zoom pre- and post-polls to gauge understanding. Participants were strongly encouraged to have their video on and to remain muted unless asking or answering a question. If participants did not comply with these requests, the program coordinator would remind them to comply via the private chat function on Zoom. The program coordinator also made the instructor and teaching assistants co-hosts so that they were also able to mute any participants if necessary. For the final session, a Nearpod presentation was created and used to further engage the participants in the whole-group discussion. After short introductions to the theory via whole group discussion, participants and teaching assistants were sent to Zoom breakout rooms for handson completion of the activities utilizing small group instruction. The transition between whole-group instruction and small-group activities was repeated several times during the ninety-minute sessions in order to retain participant engagement. During the breakout sessions, the instructor was able to enter and exit breakout rooms and was also able to temporarily work in the main room with any participant that required more individual attention. In order to easily maintain communication throughout the session, all teaching assistants, instructors, and the program coordinator remained signed on to the Slack workspace. The Zoom chat was reserved for work with the participants during the whole-group instruction.

Each day of the Academy, participants were assigned short activities to be completed asynchronously before the upcoming session. To facilitate the outside work, a website was created using Google Sites and was populated with all activity manuals (including gifs, when appropriate to aid understanding) and short videos of the hands-on activities. This was also very helpful to any participants that were unable to attend any session for personal reasons or due to technical difficulties. A link to the Google Site and reminder of the assignment was emailed to all participants at the end of each day of the Academy. Additional support, in the form of "office hours" was offered each day of the Academy and was staffed by teaching assistants and instructors.

Participants were able to ask any questions that were generated during the session and also to seek assistance with any activity.

\section{Academy Activities}

Specific activities completed on each day of the Engineering Academy are discussed below.

\section{Day 1: 3D Design of a Mask Holder and Lantern (Related disciplines: Mathematics and Engineering)}

Participants were introduced to the Autodesk Tinkercad, a web browser software for 3D design and engineering, to design 3D models through the use of concepts taught in middle school mathematics. Given the increased use of face masks due to the pandemic, the participants were encouraged to build a mask holder as shown in Fig. 1 as well as a second project of a lantern. The mask holder was used to help participants get used to TinkerCad design and familiarize them with the software functionality. Later, participants were assisted to design a lantern of specific dimensionality decorated with their individual preferences. Participants were instructed in the use of TinkerCad Design synchronously and then completed their design after the Academy hours. The participants' designs were collected by teaching assistants and checked for accuracy and completion through the TinkerCAD classroom. The TinkerCad classroom is a collaborative platform that allows instructors to view and to modify participant projects. The completed projects were printed in the University lab by $3 \mathrm{D}$ printers and mailed to the participants before the last day of the Academy. 


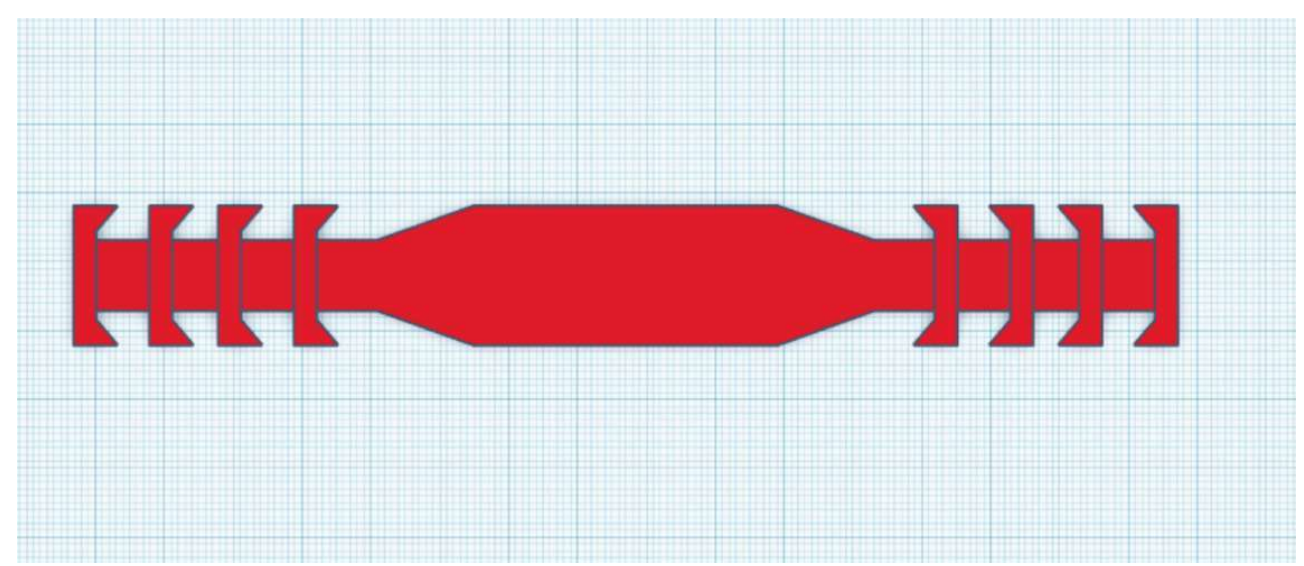

Fig. 1: 3D design of the mask holder.

Day 2: Circuits \& Conductivity (Related disciplines: Engineering, Technology, and Applied Science) Participants were introduced to basic electrical engineering concepts, including conductivity and electric circuits and components. Participants used common electronic components such as a light emitting diode (LED) in series with a resistor and a battery pack. To illustrate the concept of conductivity and connect the components above, a Play-Doh $\odot$ (conductive material), as shown in figure 2, and a plastic lid (an insulator) were tested in an experiment to create a closed circuit and light up the LED. Lastly, a breadboard was used to insert the components and complete a full circuit.

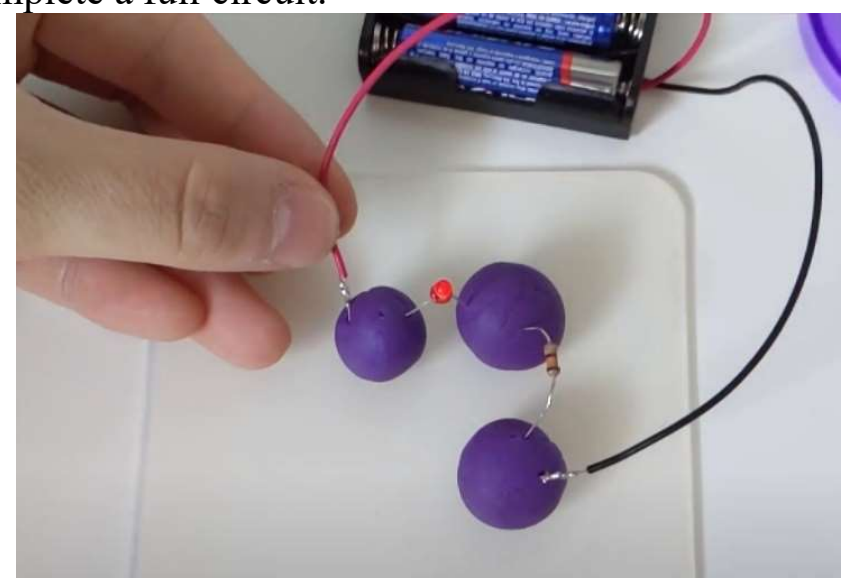

Fig. 2: Play-doh conductivity experiment.

\section{Day 3: Smart Street Light Hardware Design (Related disciplines: Engineering, Technology, and Applied Science)}

An introduction to engineering design cycle that included design, simulation, prototyping, and production was delivered on the third day. The focus was on the simulation phase of the cycle where participants were given hands-on experience using TinkerCAD Circuit, a circuit simulation software. The participants simulated on the computer the same circuit from day 2 to illustrate the initial phases engineers go through during a design. To build upon concepts learned and components used, few sensors and integrated circuits were added to the design to construct the full hardware of a smart street light in figure 3. Smart street lights are the public street lighting that adapt to the light in the surrounding where they are automatically turned OFF or ON during the day and night respectively. To add functionality to the design, a simple introduction to programming was done where participants wrote a simple code to make an LED blink. 


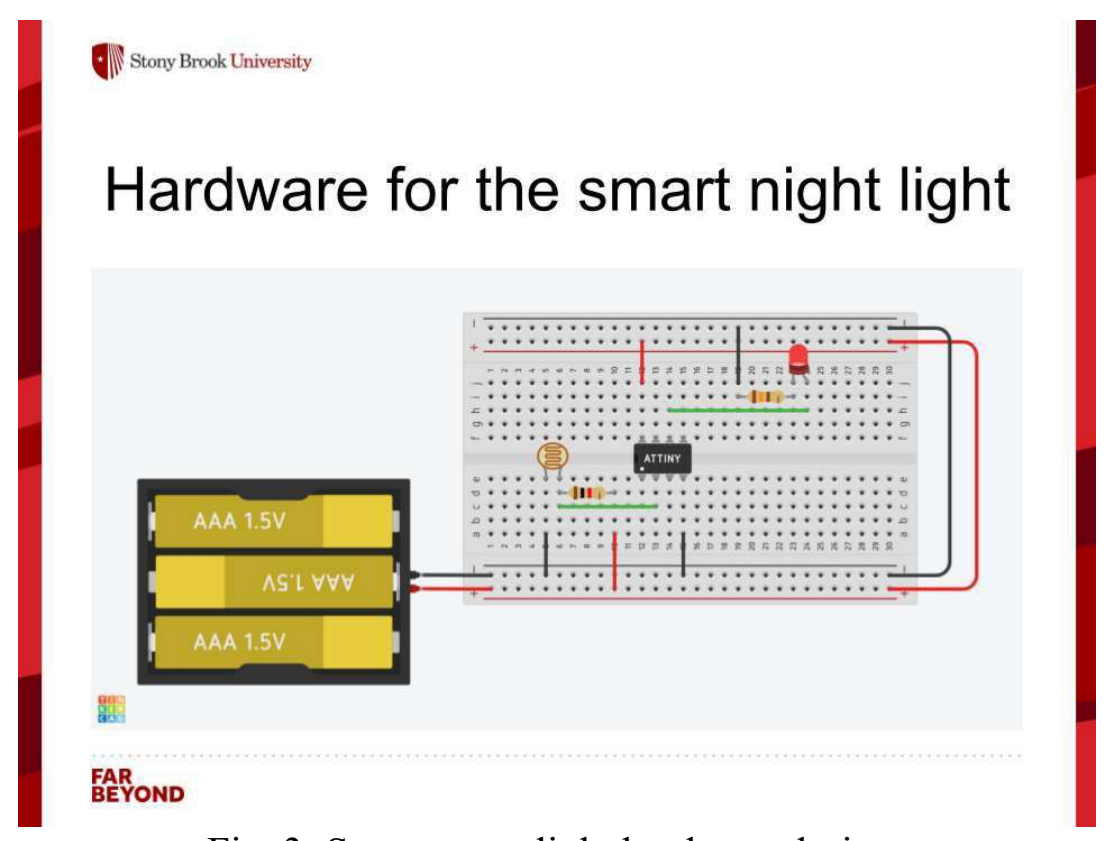

Fig. 3: Smart street light hardware design.

\section{Day 4: Smart Street Light Software Design (Related Disciplines: Engineering, Technology, and Applied Science, Computer Science)}

Participants were synchronously instructed to write a fully functional code of the smart street light. Concepts such as if-then-else logic and conditional statements were taught. After the simulation phase, participants prototyped the smart street light circuit hardware. A pre-programmed chip, that mimicked the functionality of the code written by participants, was mailed to participants early on. Adding the chip to the design completed the prototype phase of the smart streetlight that takes after the smart public street lighting design that we observe on the streets of smart cities.

\section{Day 5: Phone Backlight and Materials (Related disciplines: Engineering, Technology, Computer Science, and Material science)}

Participants learned how engineers can utilize the same electric components to design a different device with different functionality. With the use of coding, participants were able to transform the smart street light hardware design into a device that mimics the behavior of a phone backlight. Then, material science was introduced to participants to encourage them to think about materials in the designing phase. Material science studies the properties of matter and is essential for engineering to understand which materials work for which applications. Participants took part in a thermal conductivity experiment between plastic and metal to study their conductivity characteristics. Finally, to illustrate a real-world application of engineering, a video recorded by an engineer at the local electric company, National Grid, was used to show participants how power stations work to provide electrical energy to the surrounding communities.

\section{Connection to NGSS}

The lessons and activities of the Academy were designed to align with the NGSS and also the New York State Science Learning Standards (NYSSLS). According to the NGSS, at the middle school level, the new standards allow educators to provide participants with interactive instruction that promotes analysis and interpretation of data, critical thinking, problem-solving, and connections across science disciplines [3]. Keeping that in mind, the lessons were also developed to encourage participants to critically think about engineering at home. This 
Academy gave participants the opportunity to engage in hands-on activities in a non-traditional educational setting.

Each lesson supported NGSS and NYSSLS by preparing participants to meet the performance expectations in the following standards:

- MS-ETS1-1. Define the criteria and constraints of a design problem with sufficient precision to ensure a successful solution, taking into account relevant scientific principles and potential impacts on people and the natural environment that may limit possible solutions.

- MS-ETS1-2. Evaluate competing design solutions using a systematic process to determine how well they meet the criteria and constraints of the problem.

- MS-ETS1-4. Develop a model to generate data for iterative testing and modification of a proposed object, tool, or process such that an optimal design can be achieved.

- MS-PS2-5. Conduct an investigation and evaluate the experimental design to provide evidence that fields exist between objects exerting forces on each other even though the objects are not in contact.

- MS-PS3-6. Make observations to provide evidence that energy can be transferred by electric currents.

The lessons were developed to integrate the three-dimensional teaching and learning models advocated in the NGSS to provide participants with the tools needed to be successful throughout the duration of the Academy. The three dimensions consist of the Scientific and Engineering Practices, the Disciplinary Core Ideas, and the Crosscutting Concepts.

The scientific and engineering dimension encompasses policies and procedures that scientists and engineers use to explain or solve real-world problems [3]. The relevant science and engineering practices utilized in the Academy, as illustrated in the activities' section above, were planning and carrying out investigations, developing and using models, and engaging in argument based on evidence [3].

The Disciplinary Core Idea dimension lays out the fundamental scientific knowledge [3]. To provide participants with this knowledge, the lessons included around 20-30 minutes of introductory lectures that followed alongside a slideshow presentation. Here, the instructor was able to elicit participants prior knowledge and hypotheses using poll questions and verbal questions. Ultimately, these lecture presentations provided participants with the information needed in order to complete the activity.

Lastly, the Crosscutting Concepts dimension provides participants with a framework for thinking across disciplines. As shown in the activities described above, participants were able to incorporate cause and effect relations, systems and system models, and energy and matter [3] in their learning by utilizing concepts of engineering design, engineering practices, coding, and material science. The influence of science, engineering, and technology on society and the natural world was presented through the activities that resembled real-world challenges engineers face and try to solve.

\section{Survey Instrument}

Quantitative and qualitative data were collected throughout the sessions $(\mathrm{N}=90)$ to measure impact.

Participants were administered pre- and post-questionnaires at every session. The set of pre- and post-questions were exactly the same and used to assess participants' engineering knowledge and interest. At the end of the 
Academy, participants were sent via an email a post-experience survey to evaluate their engineering selfefficacy related to their interest in engineering majors and careers and their comprehension of engineering concepts explained during the Academy. The survey was created and validated by engineering faculty.

Pre and post multiple-choice questions administered throughout the Academy included:

1. What does the term 'dimensions' mean when referring to a 3D design?

2. A Play-doh is made of Flour, Sea salt, and water. Do you think a play-doh can conduct electricity and why?

3. An electric circuit is an open loop that allows electric charges to flow.

4. Resistor resists the flow of charge in an electric circuit. We measure resistance in Ohms. If we have $100 \mathrm{ohm}$ and 10 -ohm resistors. Which resistor would resist the flow of charge more?

5. If I connect a bulb (LED) to a battery WITHOUT a resistor. What do you expect to happen?

6. Why do Engineers use breadboards and Tinker Circuits before finalizing their product?

7. According to what does a Photo-resistor change its value?

8. What is the purpose of the microcontroller we are using in our design?

9. What is the print of this code?

$$
\mathrm{a}=5
$$

$\mathrm{b}=4$

if $\mathrm{a}<\mathrm{b}$

print ("a is less than $b "$

else

print ("a is greater than $b ")$

10. Where would a cube of ice melt faster: on a plastic or metal plate?

The post survey included some of the above questions along with engineering self-efficacy rating questions below. Participants rated each question by picking the following responses: strongly agree, agree, neutral, disagree, or strongly disagree. Given the post survey was administered through an email and after the end of the Academy, only $\mathrm{N}=29$ responses were received.

1. I am confident with what Engineering is (72.4\% Agree, $24.1 \%$ Neutral)

2. The remote Engineering Academy increased my interest in engineering and science careers $\mathbf{( 6 8 . 9 \%}$ Agree, 24.1\% Neutral)

3. I can see myself pursuing a career in engineering or science. (37.9\% Agree, $\mathbf{3 7 . 9 \%}$ Neutral)

4. I understand how engineering and science careers/majors are related to concepts I learned in my science classes in school (72.4\% Agree, $20.7 \%$ Neutral)

\section{Results}

The effectiveness of engineering outreach programs has been shown in research. To measure the effectiveness of the remote Summer Engineering Academy, a paired-samples t-test was conducted to compare the mean composites question scores pre- and post-each session. Results show that participants' engineering knowledge and interest significantly improved post Academy $(\mathrm{t}=7.027, \mathrm{df}=69, \mathrm{p}<.001)$ from average of pre-session questions ( $\mathrm{M}=3.95, \mathrm{SD}=1.83)$ to post-session questions $(\mathrm{M}=5.26, \mathrm{SD}=1.69)$, with a large effect size (Cohen's $\mathrm{d}=1.56)$.

In addition to the quantitative data, there were some qualitative indications that the Academy was a success. Nearly all the participants that registered for the Academy and attended the first session attended all sessions, indicating a high retention in interest and engagement. Given that the Academy was conducted during the summer after a school year that concluded with all schools 
closed and remote learning as the standard for education, it is especially noteworthy that the participants were enthusiastic about further remote learning opportunities. We also received emails from parents and from participants and have included some comments below:

"Both our children XXXX and XXXXXX are super excited after the first class."

"I had the idea that I wanted to build a robotic arm to help my mom with daily chores. It's not really an original design though. I've attached my design and a few pages of ideas that I wrote down last night to thisemail."

"Thanks so much for this great opportunity. My husband lost his job so we are really grateful for the ability forour daughter to participate in something so meaningful for free. It has been a very lonely and disappointing time and this has brightened her week. She is learning a lot and really likes the activities. She wasn't confident in her abilities prior to starting but feels more confident with each class and would like to do the two additionalclasses."

"XXXXX enjoyed this academy. This will sound strange but would you happen to know of engineering and/orscience learning opportunities similar to those experienced during academy?"

\section{Insights on Limitations, Challenges and Best Practices}

While the Academy was a tremendous success, it also presented with some challenges and created opportunities for improvement in future endeavors. Because it was a pilot program, the team was able to learn from the limitations and use them to prepare a better experience. The challenges were found in the limitations of Zoom, the use of specific devices when accessing the Academy and in maximizing our ability to instruct and to answer questions remotely. In order to maximize the pilot experience, a Professor of Engineering was invited to observe several of the sessions and offer feedback. Some of the suggestions were incorporated in planning for future sessions.

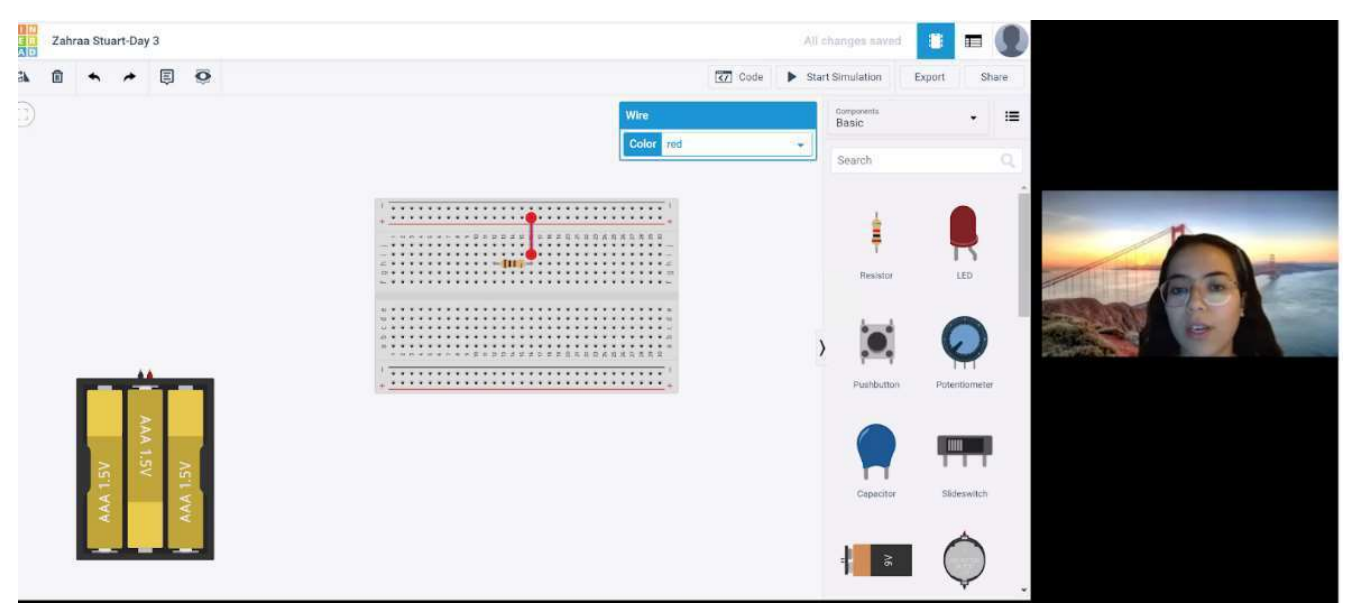

Fig. 4: Zoom meeting in session with TinkerCad activity.

Like so many educators, the instructors and teaching assistants were relatively new to using Zoom for instruction and decided to utilize the poll function in order to have participants answer questions during the sessions. Unfortunately, because participants did not have to register through Zoom, some had their names not 
always recorded by the platform and instead were listed as "guest". This made correlation of answers to preand post-questions very challenging and sometimes impossible. This also made data sorting very timeconsuming and challenging. When subsequent Academies were conducted during the fall, Google Forms, with an option to collect email addresses, was used for polls which greatly simplified data collection and analysis.

Another issue that arose during the Academy was in the use of specific technologies for accessing the sessions. TinkerCad is a free online platform that was used to create files for 3D printing and to provide simulations for the Smart Street Light. Unfortunately, during the Academy, it was found that TinkerCad does not work well on tablets or smartphones. Participants that used laptops, desktops or chromebooks had a much easier time accessing the platform. For future Academies, participants will be told in advance which devices are necessary. There were some issues in working with software differences between PC and Mac computers. While this was relatively minimal, it is worth noting that preparation should be made when working remotely with participants that use different devices to mitigate any potential problems.

As the participants attended many different school districts and had a wide variety of background information in the use of technology and experiences with engineering education, this created some particular challenges for instruction. In addition, participant familiarity with technology was also greatly overestimated and this created problems with time management. For example, many participants were unaware of how to use the split-screen mode on their devices and time was needed to guide them through the process. During the Academy sessions, it was very important that participants were able to simultaneously view the Zoom meeting and also to view TinkerCad, so a split screen was essential. In addition, participants had varying degrees of competency in accessing and using the online programs that were used. To overcome this, instructions needed to be repeated and revised to enable all participants to fully understand. This caused some frustration in participants that were more competent. Time for specific instruction on the use of technology in each of our sessions has now been included in subsequent Academy sessions. It is especially important that any Academies use platforms that allow for collaboration between participant and instructor, in order to minimize any problems that arise from participants' inadequate proficiency in technology.

In addition, there were intermittent problems with WiFi at the participant locations. This was largely unavoidable but did create logistical problems when participants were logged off and then attempted to log back on. If the session was in break-out rooms, participants were not able to access the rooms. This was managed well, by having the program coordinator as the host of the Zoom session and remaining in the main room. In this way, one person was directly responsible for managing the logistics of the session. This included managing participants, launching polls and creating and managing breakout rooms. Instructors and teaching assistants were co-hosts so that they had the ability to mute participants if needed, but were not tasked with the additional burdens of managing the session. For large group sessions, it is highly recommended that the role of a "session manager" to oversee the logistics be incorporated into the planning, leaving the instructor to manage instruction.

While all instructors and teaching assistants quickly adapted to the remote instruction, it was found to be challenging to allow participants to see the projects close enough as they were being demonstrated. The use of relatively inexpensive document cameras by the instructors and teaching assistants have made this much easier. In addition, it was difficult for the instructional team to view participants' projects clearly through their screen. By modifying the instructional approach to include the aid of online software tools which allow collaboration, instructors are able to view projects clearly and to modify if necessary. Participants then have the ability to see 
the simulation when creating the actual prototype. This has been helpful for participants and for the instructional staff.

\section{Conclusion/Discussion}

When the COVID-19 pandemic forced the closure of schools and eliminated the ability to present in-person workshops and summer camps, it became necessary to re-imagine teaching and learning through the lens of remote instruction. It created challenges and also opportunities for innovation in teaching methods. The Summer Engineering Academy was an opportunity to pilot a remote, hands-on instructional strategy and engage students in the engineering design process. The majority of participants in the Summer Engineering Academy showed increased interest and understanding of the engineering design process, as well as increased self-efficacy in engineering. Both qualitative and quantitative data analysis showed that the Academy was a tremendous success.

The model of both synchronous and asynchronous learning in the Academy can be easily replicated by others. Since it is difficult for almost all students to spend an extended period of time in front of a computer for learning, the blend of synchronous instruction followed by guided asynchronous instruction made this Academy very successful. The use of online technologies, such as Zoom, allow relatively easy access to all participants. Platforms which allow collaboration between instructors and learners, such as TinkerCad and NearPod, increase student engagement and also permit the instructor to have direct access to participant work and make it easy for instructors to directly work with learners. The access to instructional manuals, illustrated with gifs and pictures to aid in understanding, made the asynchronous learning more accessible for participants and helped in the differentiation of instruction for learners that are better suited to reading than to oral instruction during the Academy sessions. Keeping a low participant to instructor ratio-maintained engagement and helped to mitigate frustration for participants with difficulty in comprehension. By offering "office hours" after the Academy sessions, participants were able to get individualized guidance in completion of the asynchronous assignments and differentiated instruction.

The use of remote instruction also permits access to a greater segment of the population. Participants that are geographically distant from a location are able to access than would normally be practical. For local participants, transportation difficulties that could exclude individuals are eliminated by the delivery of remote instruction. Remote instruction is also cost-effective as the cost for mailing materials is mitigated by the lack of expenditures typical for in-person instruction, such as building access, insurance, and other incidental expenses. As society slowly transitions back to in-person instruction and activities, remote instruction may still be retained as a valuable tool in providing opportunities to a wider range of participants.

\section{Acknowledgments}

The authors would like to thank the support of NSF under award \#1850116 and \#164705, as well as the industrial partners, PSEG and National Grid.

\section{References}


[1] J. Larson, and L. Archambault, "The extent of k-12 online teacher development: A disconnect between preparation and practice," in Handbook of Research on Emerging Practices and Methods for K-12 Online and Blended Learning, pp. 57-77. IGI Global, 2019.

[2] J. Larson, and K. Farnworth "Crisis Teaching Online: Reaching K-12 Students through Remote Engineering Lab-Based Activities During the COVID-19 Pandemic." Advances in Engineering Education, vol. 8, no. 4, 2020,

[3] NGSS Lead States, "Next Generation Science Standards: For states, by states," Washington, DC: Achieve, Inc., 2013 Accessed: January 30, 2021.

[4] R. Lammartino, J. Bischoff, C. Willy, and P. Shapiro, "Emergence in the US science, technology, engineering, and mathematics (STEM) workforce: An agent-based model of worker attrition and group size in highdensity STEM organizations," Complex \& Intelligent Systems, vol. 2, no. 1, pp. 23-34, 2016.

[5] T. Moore, K. Tank, A. Glancy, and J. Kersten, "NGSS and the landscape of engineering in K-12 state science standards," Journal of Research in Science Teaching, vol. 52, no. 3, pp. 296-318, 2015.

[6] J. Vennix, P. Brok, and R. Taconis, "Do outreach activities in secondary STEM education motivate students and improve their attitudes towards STEM?," International Journal of Science Education, vol. 40, no. 11, pp. 1263-1283, 2018.

[7] R. Tillinghast, D. Appel, C. Winsor, and M. Mansouri,"STEM outreach: A literature review and definition," IEEE Integrated STEM Education Conference (ISEC). IEEE, 2020, pp. 1-20.

[8] J. P. Overschelde et al., "Project Lead The Way students more prepared for higher education,"American Journal of Engineering Education (AJEE), vol. 4, no. 1, pp. 1-12, 2013.

[9] S. Douglas, "The infinity project: Digital signal processing and digital music in high school engineering education," in Proceedings of the 2001 IEEE Workshop on the Applications of Signal Processing to Audio and Acoustics (Cat. No. 01TH8575). IEEE, 2001, pp. 1-6.

[10] B. Britsch, K. Peterson, and R. Marra, "The national girls collaborative project: Building capacity through collaboration," Women in Engineering ProActive Network, 2008.

[11] Z. Krayem, A. Kelly, M. Bugallo, D. Westerfeld, R. Gearns, and K. Westervelt, "Precollege electrical engineering outreach: The design of a home security system," in Proceedings of the 2018 American Society for Engineering Education Annual Conference \& Exposition (ASEE), 2018.

[12] Z. Stuart, A. Kelly, and M. Bugallo,"University-designed middle school science experiences aligned with NGSS," in Proceedings of the 2020 American Society for Engineering Education Annual Conference \& Exposition (ASEE), 2020. 
[13] Z. Krayem, A. Kelly, J. McCauley, and M. Bugallo, "Engineering exposure for pre-college women: A university-based workshop model," IEEE Integrated STEM Education Conference (ISEC). IEEE, 2019, pp. $156-159$.

[14] A. T. Jeffers, A. G. Safferman, and S. I. Safferman, "Understanding k-12 engineering outreach programs," Journal of Professional Issues in Engineering Education and Practice, vol. 130, no. 2, pp. 95-108, 2004.

[15] M. J. Mohr-Schroeder, C. Jackson, M. Miller, B. Walcott, D. L. Little, L. Speler, W. Schooler, and D. C. Schroeder, "Developing middle school students' interests in STEM via summer learning experiences: See Blue STEM Camp," School Science and Mathematics, vol. 114, no. 6, pp. 291-301, 2014.

[16] M. Bugallo and A. Kelly, "Engineering outreach: Yesterday, today, and tomorrow," IEEE Signal Processing Magazine, vol. 34, no. 3, pp. 69-100, 2017.

[17] M. Bugallo and A. Kelly, "A pre-college recruitment strategy for electrical and computer engineering study,” IEEE Integrated STEM Education Conference. IEEE, 2014, pp. 1-4. 